\section{Interviewing children and young people}

apply to any online surveys in which respondents were routed to the client's website at the end of the interview. MRS has also updated its 'Regulations on Using Research Techniques for Non-Research Purposes' to reflect this ruling, and is introducing a new guideline covering the use of incentives.

The second main change is to remove the anomaly that allowed under 16s to be interviewed on-street without parental (or a person acting in loco parentis) consent, bringing this interview method into line with all other methods.

A third change is to underline the importance of gaining the respondent's permission to be re-interviewed at the initial interview.

Finally, the definitions in the Code have been widened to reflect the impact of new research methodologies that do not always involve a traditional interview with a respondent, such as in web 2.0 research.

The revised Code and associated Regulations and Guidelines can be found on www.mrs.org.uk

Peter Mouncey, FMRS F IDM

peter.mouncey@zen.co.uk

\section{Alastair Tempest, Director General, Federation of European Direct and Interactive Marketing (atempest@ fedma.org)}

Goetz Brandau, Legal Affairs Manager, Federation of European Direct and Interactive Marketing (gbrandau@ fedma.org) info@fedma.org

\section{Whither data protection Law?}

\section{Data protection in Europe - A cloudy future}

\author{
Alastair Tempest and Goetz Brandau
}

Journal of Direct, Data and Digital Marketing Practice (2010) 12, 180-193. doi:10.1057/dddmp.2010.30

The European Convention of Human Rights supported by the Data Protection Convention (109) of the Council of Europe, enshrines privacy as a human right in Europe. This may suggest some ancient and well-established body of law buried deep in European history perhaps dating back to the French Revolution, or deeper into the mists of time to one of the great medieval bills of rights - the Magna Carta, or the Basque Constitution of Guernica, for example. In fact, as the poet Milton put it ' ... to the public good/Private respects must yield', few in the past recognized a need for a right to privacy - 'an Englishman's house is his castle', but there were always major caveats, in particular the right of the state (public good) to intervene. It took the collection of personal data designed to subjugate the individual in the mid-twentieth century to waken a real desire to safeguard privacy. 
Data Protection regulations, therefore, are relatively new in legal history - but, as this article will show, an 'industry' based on privacy is growing fast globally. The impetus is coming from Europe.

The European Union (EU) adopted a general directive on data protection (95/46/EC) in 1995, and followed that with a directive on ecommunications and privacy in 2002 (recently reviewed as part of the 'Telecoms Package'). In addition, the EU adopted the Database Protection Directive (96/9/EC) to provide a sui generis copyright protection for databases in 1996, and a directive on the Retention of Data (2006/24/EC) in 2006, which is intended principally to give governments access to communications records for up to 2 years.

Although since 1995 vast changes have taken place in communications, and use of personal data in all respects, the 1995 EU Directive has remained remarkably future proof and media neutral. The question is whether the European Institutions will let it remain more or less unchanged or will decide to completely rewrite it when they come to proposing a review at the end of this year or early in 2011.

At the end of 2009, the European Commission (EC) launched an online consultation with various alternatives for a new, revised directive. The supposition in this consultation was that because, since 1995, so much had changed in the way data can be collected and processed and, even more so, the sheer amount of information that is collected, especially online, a new directive, or a serious review of the present directive, was called for. The authors believe that, while it is certainly true that the EC should clarify some issues that are not clear in the existing text, the present directive should not be amended. It serves its purpose very well, and as the saying goes - 'if it ain't broken then don't mend it'.

Let us look at the present directive, and then at the new elements in commercial communications, which some regulators use to justify a major revision of the 1995 Directive.

Probably the weakest aspect of the present Directive is that it tries to cover far too much. It relates to both manual data and 'automatic' (ie computer) data processing. It also covers the processing (that is the collection, processing and use of personal data) by governments, commercial interests and individuals. However, one could also see its broadness as a strength, because, due to its nature as a framework directive, it establishes certain data protection principles that apply to any form of processing, no matter for what purpose. The problem of any general legal instrument covering government data processing is that this very soon bumps into serious vested interests - health ministries, employment ministries, police and the security services, etc - none of whom (particularly the last two) like to be restricted by the general principles of data protection laid down in the directive.

The debate around the directive therefore has many other facets than simply the use of personal data for marketing, as a conference held by the EC in March 2009 very clearly proved, and in the end when regulations are decided, governments will usually protect their own interests at the expense of any commercial concerns. 
Table 1: Applicable Law

\begin{tabular}{|c|c|c|c|c|c|c|}
\hline \multirow[b]{2}{*}{ Cases } & \multicolumn{4}{|l|}{ Facts } & \multicolumn{2}{|c|}{ Law applicable } \\
\hline & $\begin{array}{l}\text { Direct } \\
\text { marketer } \\
\text { established } \\
\text { in }\end{array}$ & $\begin{array}{l}\text { Data } \\
\text { Controller } \\
\text { established } \\
\text { in }\end{array}$ & $\begin{array}{l}\text { Data } \\
\text { Processor } \\
\text { established } \\
\text { in }\end{array}$ & Data from & $\begin{array}{l}\text { To the } \\
\text { respective } \\
\text { processing }\end{array}$ & $\begin{array}{l}\text { To security } \\
\text { measures }\end{array}$ \\
\hline $1 \mathrm{st}$ & $\mathrm{BE}$ & $\mathrm{BE}$ & $\mathrm{BE}$ & EU EEA US & $\mathrm{BE}$ & $\mathrm{BE}$ \\
\hline 2nd & $\mathrm{BE}, \mathrm{NL}, \mathrm{UK}$ & $\mathrm{BE}$ & $\mathrm{NL}, \mathrm{UK}$ & EU EEA US & $\mathrm{BE}$ & $\mathrm{NL}$, UK \\
\hline $3 r d$ & $\mathrm{BE}$ & $\mathrm{BE}, \mathrm{NL}, \mathrm{UK}$ & FR & EU EEA US & $\mathrm{BE}, \mathrm{NL}, \mathrm{UK}$ & FR \\
\hline 4th & $\mathrm{BE}$ & $\mathrm{BE}, \mathrm{NL}, \mathrm{UK}$ & ES, PT, LUX & EU EEA US & $\mathrm{BE}, \mathrm{NL}, \mathrm{UK}$ & ES, PT, LUX \\
\hline
\end{tabular}

The EC's conference identified a series of issues that the Commission felt needed to be addressed, including the commercial use of data collected online, and marketing data. However, the issues that created real debate and discussion revolved around the processing of public data - that is, collection/processing/use of personal data by public entities, and how these institutions often manifestly failed to protect the individual - for example, by inadequate security (data breaches), or excessive requests for data (US requirements for airline passenger information). Many speakers criticized that communications data, which service providers are forced to collect to support the fight against terror, are routinely accessed by law enforcement for the investigation of all sorts of crimes. Connection data from mobile phones are regularly used for the investigation of crimes that cannot be considered 'terrorism' and that do not pose a risk to someone's life ... although the Data Retention Directive aimed to protect privacy by allowing the use of such data only in case of 'serious crime'. Delegates asked 'are governments seriously applying the basic principles of the existing Directive?'

What are these principles that the directive sets down? Some experts say that there are eight. We believe that there are in fact nine, as follows:

\section{The DP principles}

1. Notice - data subjects should be given notice when their data are being collected;

2. Purpose — data should only be used for the purpose stated and not for any other purposes;

3. Opt-out - the right of the data subject to object to their data being processed;

4. Consent - when consent is required, it should be freely given, specific and informed;

5. Security - collected data should be kept secure from any potential abuses;

6. Disclosure - data subjects should be informed as to who is collecting their data;

7. Access — data subjects should be allowed to access their data and make corrections to any inaccurate data;

8. Accountability - data subjects should have a method available to them to hold data controllers accountable for following the above principles; and 
9. Fair Balance - there should be a fair balance between the rights of the individual to protect his/her data and the needs of legitimate users (commercial or government) to access and use personal data.

These principles should appear in every national data protection regime, but one of the major problems of data protection legislation in Europe is its numerous variations from country to country. This makes the task of the marketer particularly challenging; however, within the existing general data protection directive lies an important principle that a database controlled in one Member State, no matter what the country of origin of the citizens whose data are in the database, applies the law of that Member State. When data are collected, the local laws apply to the collection (for example, the security aspects); but once in a centralized database, one law applies. This is only logical: it would be impossible to apply all national data protection rules - some of which are even contradictory, and in particular online where the country of residence of the citizen ('data subject') may not be clear.

To clarify this aspect further the Federation of European Direct and Interactive Marketing (FEDMA) negotiated a code of conduct with the national data protection authorities (DPAs), which came out with the following (Table 1):

In the submission of the FEDMA, which is echoed in a number of other submissions, we said that:

The spread of new technologies and the increasingly globalised economy have led to an increase in the number of data processing operations and databases. In addition, today's economic activities often require data to be transferred and moved between different locations, which may be within the EU territory or in third, non-EU, countries.

In light of these developments and due to the higher amount of data processing operations that are taking place, it has become challenging for enforcement bodies to apply the regulations coherently. As a consequence, enforcement has turned out to be patchy at times, which raises serious concerns for law-abiding businesses. (See Section III — 'Enforcement and Implementation'.) Enforcement bodies have also been slow in publishing guidance on their interpretation of how the data protection principles are to be applied to new technologies. In the past years, there has been a lack of transparency in the work of some of the enforcement bodies, and in many cases an absence of a constructive dialogue on these issues with industry stakeholders. As a consequence, the direct and interactive marketing industry across the European Union faces problems today that have their origin in the incoherent interpretation and application of data protection regulations. ${ }^{1}$

\section{Applicable laws and} national differences
It is perhaps one of the greatest and most persistent mistakes of politicians that they attempt to solve the failure of effective enforcement by calling for more and stricter regulations. In the case of this directive, the EC, which is charged with ensuring the correct 


\section{Trying to control national differences}

implementation at national level of directives and regulations, has not been active in pursuing those Member States that have failed to apply the rules, except in a few cases, mainly where the national laws have been too liberal. This has given the clear impression to Member States that they can restrict further than the directive requires, but not less. In fact, as the Commission official who originally drafted the Directive pointed out frequently the Directive has 'a ceiling and a floor' below and above which Member States are not supposed to go. Using this example, the EC has taken corrective action against those countries whose national data protection legislation stayed under the 'floor', but not against those countries whose legislation went 'through the roof'.

The 1995 Directive recognized that there would be differences in national application of the Directive, and it therefore created three separated mechanisms to try to ensure that these differences were tackled and removed - or at least reduced to a manageable level.

The first two of these mechanisms rely on what the EC calls comitology - official standing Committees, serviced by the EC, which are charged with discussing (and therefore implicitly reducing) differences in the implementation and enforcement of the Directive. The first of these Committees is the so-called Article 29 Working Party consisting of the national DPAs, which produce opinions and also (see below) agree European codes of practice.

The second is the Article 31 Committee made up of the regulators from each Member State; mainly Ministers of Justice, but also including some DPAs, this Committee is less obvious to outsiders. Issues raised there may influence national government policies, however, in ways in which these lines of communication work are hidden. Once the Directive is revised, however, these will be the national civil servants who will be responsible for their government's input through the Council of Ministers. There is also a major crossover with the national representatives at the Council of Europe.

Finally, and much more adventurously, the EU agreed in Article 27 of the Directive to national codes of conduct to be negotiated with the national DPAs, and opened the way for European negotiated codes. The Directive's authors intended that these codes put pressure on national governments to follow a specific interpretation of the various issues. European codes are meant to establish a framework, to set up limits, to which the national codes have to be adapted when they are drafted. However, the only code under this article so far has been negotiated with FEDMA on the use of personal data for direct marketing purposes, although the International Chamber of Commerce (ICC) together with other associations, including FEDMA, has negotiated Model Contract Terms for Controller to Processor, and Controller to Controller. The ICC has also been successful in getting the terms and conditions for Binding Corporate Rules agreed with the Article 29 Working Party. But still the only negotiated code of conduct is the FEDMA code of 2003, with an Annex specifically for online issues, which was adopted in July 2010. 
In those countries where codes are used extensively (eg France, the UK and the Netherlands - which specifically incorporates codes into the law), many professional bodies (doctors, dentists, etc), as well as a wide range of trade associations have negotiated codes with their national data protection authority (DPA). This process is usually known as 'co-regulation' to differentiate it from self-regulation (adoption of codes by the industry for the industry but usually using an independent enforcement mechanism - a Self-Regulatory Organization, SRO).

Certainly, the very long lag time between the first proposals for a code in 1996 and the adoption of FEDMA's code in 2003 by the Article 29 Working Party must have put off a lot of potential trade and professional bodies. There is also not the same level of interest at European level as there is at national level, and some of the largest players are concerned that if they sign off on an EU code their corporate headquarters could be held to it in the USA.

There is also a lack of hard evidence to show that codes are helpful in the long term. We believe this is a 'self-fulfilling prophecy' if a sector or profession is not prepared to enter into a code-making negotiation with the authorities, it is certainly not going to see the benefits of such a code. The FEDMA code has been picked up in many countries by the national direct marketing association and DPA and used as the national code, perhaps with some specific national additions/revisions. The objective of a code is principally, in our view, to provide an interpretation of the law written in a language that business can follow on a daily basis, without the need for legal advice. Ideally, a code contains examples to guide the user. A secondary objective may be to add to the legal requirements - for example, by covering an issue not covered adequately in the law, and thus do away with the need for additional regulation. In FEDMA's case, a section on children (with a very useful age definition) was included. The issues of marketing to children remain top of mind as the Commission moves forward on its revision of the Directive. Together with health and financial data, data collected on children will be very important in the revision process.

The USA, which lacks a general privacy law, does have a number of strong federal laws on specific forms of personal data - precisely on children (COPPA); data on personal financial aspects, and health data. In order to achieve a modus operandi, the EU Commission and US Federal Trade Commission operate the so-called Safe Harbor agreement that requires US signatories to apply EU data protection standards to European personal data that a company holds in its US Databases.

It is interesting to pause at this moment and wonder what would be

Will new EU regulation cause the migration of databases outside the EU? the logical result if the principle of 'country of origin' control, which we mentioned earlier when outlining the General Data Protection Directive, was removed during the promised revision of the Directive. As we saw, this principle allows a data controller to apply only one set of laws to his/her database, and not have to apply all 27 national laws. This same principle applies to the Safe Harbor - there is one general set of principles for the processing of data in the USA by signatory 


\section{Internet, the global medium}

companies to the Safe Harbor. If this principle of one set of rules changed in the EU, but remained the same under Safe Harbor, we believe there would be a very serious migration of databases towards the USA, with serious economic fallout for all data processing businesses in the EU.

As mentioned earlier in this article, it would present data controllers operating a database with the insurmountable task of applying the data protection law of each data subject's country of residence when processing personal information. This would create significant problems for data controllers, data processors and data subjects alike. Such a change would lead to an explosion of administrative costs related to the maintenance and operation of an international database, either caused by legal compliance cost or by requiring companies to operate databases in each country that it operates in. At the same time, such a change works contrary to the underlying principles of the data protection directive, which is to protect the right to privacy with respect to the processing of personal data, and to prevent the restriction and the prohibition of the free flow of personal data between Member States. Introducing the 'country of destination' principle into EU data protection legislation would result in such an undue restriction of the free movement of personal data within the EU.

Equally important, it needs to be pointed out that such a change would only lead to marginal improvements, if any at all, in the protection of data subjects' personal data because the data protection directive already guarantees that all personal data processed in the EU are covered by an adequate level of protection. In order to be able to apply the appropriate level of protection to the personal data stored in a commercial database, the company would need to collect additional categories of information about each data subject, for example his/her country of residence, which is contrary to the 'data minimization' principle, whereby companies should collect and process as little personal data as possible for specified purposes.

This brings us to the 'new' global environment for personal data, and the reason why the EU Commission is claiming that the Directive 46/95 needs revision.

Many commentators have pointed out that information, including personal data, is the life-blood of the internet. Mankind has taken one of its occasional great leaps forwards - and moved from being local/ national/regional to being global, thanks to the internet. Anyone can create a website, or a blog. We can all upload material (photos, videos, views, etc) to Facebook or YouTube, or create business/personal communities on services such as LinkedIn. But the internet is not only a social space to make connections, but most importantly a channel to conduct business. It facilitates more efficient communication, allows for instant personalization and provides access to service providers and traders who were previously excluded from certain markets.

The internet is the zeitgeist of this generation - and it has spawned a wide array of new communications tools, which can be used for personal and commercial use - blogs, twitter, mobile internet (3G), 
etc. All these rely on information being processed and made available on a constant basis, and much of that information relates directly or indirectly to individual persons - and is therefore subject to data protection regulations.

An issue that is much debated today is where the line between

What is personal data online? personal data and impersonal data has to be drawn. For example, is a computer's IP address personal data or not? Some experts argue that since PCs are usually mainly operated by one person, either at the office, or (perhaps less so) at home, the IP address can be traced back to an individual and is therefore personal data. Others disagree; in France, for example, the courts held that IP addresses are not personal data.

At present, the importance of this discussion over what is, or is not, to be included as personal data centres on the debate about online behavioural advertising (OBA), online profiling and related techniques used to target content or advertising messages at consumers according to their preferences. Many opinion makers (on both sides of the Atlantic) are stirred up by concerns that existing tools on data protection fail to adequately protect consumers from large-scale collection of data related to their activities online. They point out that by collecting information about a consumer's behaviour over time it is possible to build a 'profile' that, although it does not contain specific data that identify an individual, represents an individual's preferences accurately enough to allow the profile builder to recognize 'the consumer' out of a group. Privacy advocates suggest that using targeting practices to an extent where an individual consumer can be singled out becomes an invasion of privacy, and therefore should be covered by data protection/privacy regulations. The same would be said of 'unique identifiers', such as internet cookies, which can be used to recognize a web browser. An initial draft for a new US Data Privacy Bill in Washington sponsored by Congressman Rick Boucher (D-VA) follows this line of argument and specifically includes in its scope any number, pseudonym or other identifier that identifies a 'computer, device or software application'.

Professionals in the targeting business tend to reject such claims on the basis that it is usually not possible to identify the individual using a computer, or possible to tell whether a machine is used by one or several different individuals. If it is indeed impossible to differentiate whether a device is used by one or more individuals, the data can hardly be considered to be 'personally identifiable', and should not fall under the scope of the EU Data Protection Directive. Following this argument, however, it could also be argued that this represents a loophole in the legislation that would be closed by extending the scope of the directive to include all data that refer to 'identifiable individuals and devices'.

At first sight, this approach may seem to improve the protection of individuals' privacy against excessive targeting and profiling. When taking a closer look, however, the shortcomings of including all identifiers, whether they refer to a device or an identifiable individual, in the definition of personal data and granting to them the protection of 


\section{What uses data are put to is important online}

the EU data protection framework become apparent. For legitimate businesses, whose interests are recognized and protected by the directive, such a significant extension of the applicability of existing data protection instruments would create serious problems and result in regulatory burdens for economic activity where this is not intended. Where data does not fit the definition of personal data, it is unlikely that the processing of such data will have a negative impact on the data subject's privacy. Therefore, it is not justified to apply additional restrictions to the processing of such data, where this does not result in improved protection of the private sphere.

The author is convinced that a different approach is not only more efficient in protecting the privacy of data subjects, but also less disruptive when integrated into the existing data protection framework in Europe. At the basis of this alternative approach lies the conviction that it is not sensible to declare IP addresses and browser cookies to be personal data without taking account of the circumstances in which they are processed. Instead of getting entangled in a misdirected debate over whether or not IP addresses are personal data, we should focus on finding workable solutions to determine the circumstances under which these types of data represent personal data, and therefore should be protected under the appropriate data protection regimes.

In order to assess whether data processed by an organization need to be qualified as personal data, it is necessary to analyse not only the type of information that is collected and processed, but also the purpose for which they are processed, other types of information that are collected or accessed in the process, etc. In recent years, data processing activities have not only grown in number, but have also become increasingly complex and therefore difficult to comprehend for outsiders. As a consequence, it may be a cumbersome and demanding task to analyse processing operations and to assess the 'identifiability' of the data - yet this should not serve as an excuse to skip this important element of applying the appropriate level of protection that respects the 'balance of interests'.

Any processing of personal information requires a legal basis in order to be legitimate. The Data Protection Directive establishes a number of criteria that are to be used in judging whether or not processing is legitimate. The past 15 years of experience with the 95/46 directive has shown that the process of applying these data protection principles of the technology-neutral directive to different data processing scenarios can comfortably be described as the most difficult part in European data protection. As challenging and resource-intensive as it may be, this task is part of the job of the national DPAs. Ultimately, it is up to them to decide whether a company processes personal data and whether there is a legitimate legal basis for this processing.

In making this assessment, two main factors have to be taken into consideration:

- Is the information that is processed 'personal information' in the meaning of the directive? 
- And is there a legitimate legal basis for the processing of this information?

When analysing whether information is personal data, all circumstances of the processing operation need to be taken into consideration. Let us use the example of an IP address: each device needs an IP address in order to be able to communicate via the internet. Although an IP address, a 32-bit (IPv4) or 128-bit (IPv6) number, by itself provides little information about the device it has been assigned to, it can be used in the more granular processing of data. For example, by using geolocation applications it is possible to determine the location of a device based on its IP address. Such a feature can be very useful in displaying the right (the local) time on a website that is frequented by international visitors, or by responding to a user's search query for 'Italian restaurant' by displaying those restaurants that are in the same city as the user (according to his IP address). Arguably, the privacy impact of this sort of processing is negligible.

But IP addresses can also be used in ways where they are closer to resembling personally identifiable information, for example where the IP address is used to track a visitor's use of a website. This issue resulted in contradicting court decisions, which serves as a good indicator of how thin the line between the two sides (personal data or not) really can be.

Although there is a strong case to argue that website operators who monitor the use of their website by tracking IP addresses do not process personal data in the meaning of the data protection directive, it is easy to imagine a scenario where one would not be able to come to this same conclusion. A website operator who stores logs of visitors to his/her website over a longer period of time, or who 'enriches' such a log with information from other sources using the IP address to match the different records, would soon find himself with data records that reveal more detailed information about the website visitors... or even identify them.

Internet service providers (ISPs) represent the other end of the spectrum. Since they assign an IP address to a device/line and have ready access to the personal contact and banking details of the account owner, IP addresses clearly match the definition of personal data when they are processed by ISPs.

This sums up why it is not helpful to argue that IP addresses are personal data under all circumstances or never; either solution has its disadvantages and would include those scenarios where IP addresses are clearly non-personal, or clearly identifiable.

Where an organization is indeed processing personal data, it is

'Fair and lawful processing' necessary to test whether there is an appropriate legal basis for this. The data protection directive does include clear (although abstract) conditions for fair and lawful processing in Article 7, which can be used for this test. For processing of personal data in a commercial context, the legitimacy is usually based on the data subject's consent (Article 7a), because processing is necessary for the performance of a contract (Article $7 \mathrm{~b}$ ), or because processing is in the legitimate interest 


\section{Enforcement of the principles at national level - inconsistancies}

of the company (Article 7f). Depending on the details of each individual processing operation, the circumstances under which these justifications are used can vary greatly. This goes in particular for processing that is based on article $7 \mathrm{f}$ of the directive. The actual wording is rather cryptic ("purposes of the legitimate interests pursued by the controller') and carries the important limitation that the legitimate interests of the data controller may never override the 'interests for fundamental rights and freedoms of the data subject'.

What does this mean in practice? Even though the EU data protection framework provides robust rules that protect the data protection interests of data subjects, it is indispensable that these technology-neutral rules are properly applied. In order to ensure the adequate protection of personal data and privacy in the information technology age, there is therefore the need for a body that is able to investigate and analyse processing operations in light of the rules provided by the legislative framework and ultimately to make decisions regarding their legitimacy. Ultimately, a data protection framework can only be as effective as the regulatory body that enforces it - and insufficient enforcement is the weak spot in an otherwise robust European data protection framework.

A modern data protection regulator is expected to manage an abundance of tasks and keep in check an overwhelming number of data controllers, data processors and activities that involve the processing of personal data. In order to ensure the protection of personal data and privacy in an increasingly globalized, fast-paced information society, one cannot afford to neglect these tasks. Unfortunately, a number of European DPAs have not evolved as fast as the industry they are intended to oversee. As a result of this lack of consistent enforcement, it was possible for some actors to get away with systematic breaches of data protection law and the well-balanced and future-looking directive has come under suspicion of being antiquated and unable to face the challenges of the development of the internet.

The rules and principles contained in the data protection directive are well suited to deal with the (technological) realities of today, as long as one applies them consistently. The shortcomings of European data protection are found in the lack of consistent and diligent enforcement of rules. They are not caused by insufficient legal protection or inadequate laws. In order to future-proof data protection in Europe, and there shall be no doubt about the importance of this task if we aspire to create an online environment that can be used by businesses and consumers alike, we need to improve the organization of the enforcement bodies. In order to handle the data protection challenges we face now and are likely to face in the future, ranging from an increase in the amount of data processing to more sophisticated targeting, and cloud computing, we need to ensure that DPAs have available the necessary tools and resources to fulfil the role that was set out for them in the Directive.

In addition to playing a more active role in the monitoring of all processing activities taking place in their jurisdiction, DPAs must 
provide industry with clear and timely interpretations of the rules in the directive and how they are to be applied to new technologies. Considering the non-national, global nature of data protection due to the internet, these decisions need to be consistent at the European and, where possible, global level. There are numerous initiatives at the European level (eg the 'Digital Agenda') that aim to promote the internal market and reap the economic benefits of the information society. But we need to be very clear that a clear and consistent application of the data protection framework is a precondition for realizing this potential; it is a key factor to enable companies to develop and invest in new business models; to create prosperity through economic activity that is not bound by national borders; for consumers to use the internet to access the wide variety of goods and services that are offered in the different EU member states; to do so in a way that is in line with a legislative framework, and create a balance between respect for privacy, security of personal information and the legitimate interests of businesses to process data. It is this balance that lies at the very centre of all European data protection instruments that we must protect and look after.

The EC is currently preparing an update of the data protection directive and announced a legislative proposal for November 2010. In this context, several issues have been brought to the attention of the Commission that supposedly warrant changes to the directive. The authors would like to use this opportunity to argue that most 'new' concerns can be addressed using the tools available under the existing legislation.

\section{The Online Behavioral Advertising debate}

The discussion on OBA and other forms of online targeting is an important one, and may actually serve as a precedent in support of our argument. Similar to the question of IP addresses, it is important to analyse whether online targeting actually uses personal information; while online marketing can be targeted to an individual consumer using personal data, in most cases advertising is targeted using anonymous information. Where targeting uses personal information, it is necessary to test whether the requirements for fair and lawful processing are met, for example has the user's consent been collected and is collection in the legitimate interest of the data controller? It is important to recognize that not all parties involved in the online targeting have a legitimate interest in processing an internet user's personal data, and it is up to the regulatory bodies to draw a line where this legitimacy ends.

When looking at the discussion on profiling and online targeting in the USA, the main concerns result from the perceived danger of excessive collection of personal data, surreptitious collection, and consequently the consumer's inability to object to any decisions that have been taken using erroneous data. These concerns are real, especially with regard to the danger of erroneous information, when considering the role profiling plays in approving bank loans or insurance coverage. And while the USA now plans to protect consumers from the unfair use of such techniques by introducing a requirement to provide notice, these issues have been covered by EU 


\section{How to deal with cloud computing}

legislation since 1995. Several data protection principles in the directive, namely data minimization, purpose limitation, right to object and fair processing (which requires notice), are intended to ensure that consumers' interests are protected when their personal data are processed. It is safe to say that some online targeting practices that are used on the internet are not in line with EU data protection legislation. But the appropriate response would be to enforce the existing legislation against those who breach it, rather than introducing additional restrictions that limit the economic opportunities or even destroy the business model of those who do abide by the high level of data protection in Europe.

In this context, 'privacy by design' and 'privacy by default' cannot be seen as new data concepts that should be introduced to the directive. They are creative names for processes that are used to comply with existing principles. How different are 'privacy by default' and 'data minimization/purpose limitation' really? The same goes for privacyenhancing technologies, which are useful tools to help businesses comply with the data protection principles, rather than a revolutionary principle.

Finally, this leads us to problems regarding the location(s) where data are stored and the question of whose responsibility their security is - how to 'control' cloud computing?

Cloud computing is high on the agenda of stakeholders and legislators because it has the potential to deliver significant benefits in the efficiency and affordability of IT services and because it can play an important role in helping companies bridge national borders and similar obstacles. IT gives reason for concern on the side of legislators because the large-scale deployment of cloud computing services will lead to the quicker movement of larger amounts of data between multiple, often international locations. This poses obvious challenges with regard to ensuring the security of data in their changing locations. This situation requires legislators and businesses to cooperate in developing procedures that make it possible to identify the party responsible for the security of data in cloud computing. Considering the potentially global impact of cloud computing, adding transparency to accountability should be achieved in cooperation with non-European states or international organizations such as the ICC. But this task offers an opportunity as well. Since 1995, businesses have voiced concerns about the complexity of rules for the approval of international data transfers. Adapting the data transfer rules to facilitate cloud computing could present a chance to reduce the complexity in order to meet the needs of businesses operating increasingly on a transnational or even global scale.

\section{Conclusions}

To conclude, we do not believe that the EU's 1995 Data Protection Directive needs a major overhaul, but we are greatly concerned that the non-enforcement of the Directive is being used by some opinion 
formers as an excuse to introduce new restrictions at the European level (and shortly thereafter at the national level). The Direct and Interactive Marketing sector needs to be active in ensuring that new and more restrictive laws are avoided.

\section{Note}

1 FEDMA Submission to the European Commission Consultation on the legal framework for data protection, 16 December 2009, http://ec.europa.eu/justice_home/news/consulting public/0003/contributions/organisations_not_registered/fedma_en.pdf. 